\title{
IRCA's impact on the occupational concentration and mobility of newly-legalized Mexican men
}

\author{
Sherrie A. Kossoudji, ${ }^{1}$ Deborah A. Cobb-Clark ${ }^{2}$ \\ 1 The Institute of Labor and Industrial Relations, Economics Department/School of Social \\ Work, 421 Victor Vaughn Building, The University of Michigan, Ann Arbor, MI 48109-2054, \\ USA (Fax: +1-734-763-0913; e-mail: kossoudj@umich.edu) \\ 2 Economics Program and National Centre for Development Studies, Australian National \\ University, Canberra, ACT 0200, Australia \\ (Fax: +61-6249-0182; e-mail: dcclark@coombs.anu.edu.au)
}

Received: 22 July 1997/Accepted: 2 February 1999

\begin{abstract}
We examine the occupational concentration and mobility of a group of unauthorized Mexican men who received amnesty under IRCA to shed light on the role of legal status in the assimilation process. Initially these men are concentrated in a small number of traditional migrant jobs. Although their occupational mobility rate is high, it partly represents churning through these same occupations. When we consider the direction - either upward or downward - of occupational change, we find that English language ability and the characteristics of the occupation, itself, are strongly correlated with mobility before legalization. After legalization, few characteristics surpass in importance the common experience of having received amnesty.
\end{abstract}

JEL classification: J62

\section{Introduction}

The public debate on unauthorized migration to the United States has revolved primarily around the concern that unauthorized workers compete with and limit the labor market opportunities of some U.S. workers. The focus is usually on the concentration of unauthorized workers in specific labor markets and jobs because evidence suggests that there are few effects on the aggregate U.S. labor market or for the typical U.S. worker. Unfortunately, the long-term implications of the presence of unauthorized workers for labor market competition have remained unclear because little is known about how 
they respond to changing economic incentives after entering the United States. If occupational concentration is a temporary phenomenon and unauthorized workers assimilate as legal immigrants are thought to do, the direct effect of their presence may diffuse without much adverse long-term impact. Understanding occupational concentration and occupational mobility over time, then, is central to understanding whether unauthorized workers reduce the labor market opportunities of specific groups of U.S. workers.

Our goal is to shed light on these issues by assessing the occupational concentration and mobility of a group of Mexican men who entered the Unites States as unauthorized workers, and then received amnesty as part of the Immigration Reform and Control Act (IRCA). In 1986, IRCA granted amnesty to 1.7 million unauthorized workers who could demonstrate continuous U.S. residence since 1982. Amnesty allowed those unauthorized residents who qualified to convert to permanent resident status and eventually to qualify for citizenship. ${ }^{1}$ In particular, we are interested in the following questions. First, how does the occupational concentration of unauthorized migrants change over time? Second, what role does legal status play in the occupational mobility and economic assimilation of immigrants? Finally, has IRCA improved the labor market opportunities of newly-legalized workers?

These questions are important because the relationship between legal status and occupational attainment and mobility is not well understood. For example, one question that has never been effectively answered is whether differences in outcomes for legal and unauthorized workers arise because of their legal status "per se" or because there is an unobserved selection process that characterizes legal and unauthorized migration. Following the same individuals through time as they change legal status reduces the selectivity problem. ${ }^{2}$ It is also important to assess how successful IRCA has been in providing more labor market opportunities. The impact of this policy shift is of interest because those individuals legalized under IRCA are now eligible for U.S. citizenship.

In the following section we consider the evidence on economic assimilation and the occupational concentration and mobility of migrants. A discussion of the impact of migrants on labor market competition is also presented. In Section III, we discuss occupational mobility as a means of assimilation and provide a theoretical framework for the occupational mobility of unauthorized workers. Following that, our focus is on the occupational concentration of newly-legalized workers at various stages in their work lives. Section $\mathrm{V}$ describes the empirical determinants of pre and post legalization occupational mobility for newly-legalized Mexican men. In the final section of the paper we conclude with some general observations and suggestions for future research.

\section{The issues}

\section{Assimilation}

For immigrants as for natives, earnings mobility is closely related to occupational attainment, occupational mobility and the process of becoming assimilated. ${ }^{3}$ Early research on the economic progress of immigrants appeared to strongly support the notion of economic assimilation. In his classic article, 
Chiswick (1978a) argued that although immigrants initially earned less than the native born, their earnings rose more rapidly with U.S. labor market experience and after ten to fifteen years exceeded those of natives with the same observed skills. This pattern either requires that immigrants will earn higher wages than natives in the same occupations or that immigrants move into occupations that have higher average earnings. In fact, research showed that the occupational attainment of immigrants rapidly improved as U.S. labor market experience was acquired supporting the latter hypothesis (Chiswick 1978b). More recent research has found similar results for immigrants to Australia (Miller 1987). ${ }^{4}$

In spite of data limitations, a body of literature has developed assessing the occupational attainment and mobility of unauthorized workers. Chiswick (1988) concludes that the occupational attainment of apprehended unauthorized workers is only marginally lower than that of recent legal immigrants from the same home country. Other research suggests, however, that occupational mobility does depend on legal status. In particular, the effect on occupational attainment of U.S. experience before legal residence status is received is significantly lower than the effect of U.S. experience after legal residence status is received (Jasso and Rosenzweig 1985, 1990). ${ }^{5}$ Kossoudji and Cobb-Clark (1996) find that unauthorized mobility exhibits the characteristic of "occupational churning" with workers changing occupations often, but within a very limited set of jobs. However, mobility also appears to differ among various groups of unauthorized workers (Jones and Murray 1986).

\section{Labor market competition}

Previous estimates of the impact of immigration on the wages and employment opportunities of U.S. workers have focused on legal immigrants. Many of these estimates were derived by estimating the technological relationships between immigrants as a whole (Grossman 1982) or disaggregated immigrant groups (Borjas 1987) and other groups of U.S. workers. In the aggregate, while immigrants are substitutes with some labor market groups they are complements with others, and their overall effect on the aggregate labor market appears to be small. More recent research takes into account the geographic and industrial concentration of migrants to better assess the implications of immigration for specific labor markets (Altonji and Card 1991; Espenshade 1992). As the domestic groups studied become more specific, and more similar to immigrants, the effect of immigration becomes stronger. Over time, however, the effects of migrant cohort size diminish, a finding the authors attribute to immigrant assimilation (LaLonde and Topel 1991).

While immigrant assimilation provides one explanation for the dissipation of competitive pressures, it is not at all clear that even long-term unauthorized workers will assimilate. The extent to which unauthorized workers compete with U.S. workers depends on the technological relationship between unauthorized and other workers, on the magnitude of the overall flow of migration, and on the behavior over time of the unauthorized workers in any cohort. Most research on the substitutability of unauthorized workers with other labor market groups has been based on case studies of selected labor markets (see GAO 1988 for a review), groups of legal Latino workers (Bean et al 1987), or census estimates of unauthorized residents in local labor markets 
(Bean et al. 1988). This literature provides a useful starting point, but we know little about how these relationships vary over time or whether they apply to larger groups of unauthorized workers. This paper fills an important void in the literature by addressing these questions.

\section{Occupational mobility as a means of assimilation for unauthorized workers}

Unauthorized workers are unique in that they are constrained to certain segments of the labor market where their illegal status is easily hidden or ignored. The potential for occupational mobility is directly affected because the set of occupations open to unauthorized workers is limited. Constrained labor market opportunities also indirectly affect occupational mobility by reducing the incentive to invest in new human capital (Kossoudji and Cobb-Clark 1997). ${ }^{6}$ Over time, however, as workers learn about alternative job possibilities, which employers are willing to hire workers without documentation, where to find false documentation, etc., these constraints may become less binding. Finally, unauthorized workers may be more likely to experience involuntary and voluntary job changes than other workers because of apprehensions or periodic return trips to their home country.

In this section, we propose a simple theoretical model of occupational mobility that takes into account the issues discussed above. In developing a theoretical framework we strove to maintain simplicity while at the same time allowing the most pertinent theoretical issues to be illustrated. We are less interested in developing an all-inclusive model of occupational mobility than in capturing the most important components of occupational mobility for unauthorized men and women.

In each period, unauthorized workers will be assumed to choose an occupation based on relative occupational earnings. The assimilation hypothesis maintains that migrants initially start low but then move upward in the occupational rankings. Our goal is to determine the labor market conditions that are consistent with this hypothesis and then to determine how legalization might affect the occupational mobility of newly-legalized workers.

Unauthorized workers are assumed to choose occupations based on occupation-specific earnings, $Y_{i j t}$,

$$
Y_{i j t}=R_{j}+b_{j}\left(x_{i t}-\bar{x}_{j}\right)-\lambda_{i j t}
$$

where $i$ indexes individuals, $j$ indexes occupations, and $t$ indexes time. In the equation above, $R_{j}$ is the earnings value of an occupation, $b_{j}$ is the return to human capital, $x_{i t}$ is an individual's human capital, $\bar{x}_{j}$ is average human capital over individuals in occupation $j$, and $\lambda_{i j t}$ is a penalty for being unauthorized. The expected earnings in an ocupation is a typical estimate for $R_{j}$. The estimate of $R_{j}$ is smaller than that under our ranking method (see the Appendix). ${ }^{7}$ The penalty for being unauthorized is given by:

$$
\lambda_{i j t}=F\left(I_{i j t}, A_{j t}, D_{i j t}\right),
$$

where $I_{i j t}$ represents the worker's U.S.-specific information about different occupations, $A_{j t}$ represents the probability of being apprehended in occupation $j$, and $D_{i j t}$ represents the direct wage penalty associated with being 
Table 1. The effect of changes in labor market conditions on the probabilities of upward occupational mobility

\begin{tabular}{|c|c|c|}
\hline \multicolumn{3}{|c|}{ Probability of choosing lower ranked occupation after migration (Equation 3) } \\
\hline Unauthorized penalty in $\mathrm{h}$ : & $\frac{\partial A}{\partial \lambda_{i h 1}}$ & Positive \\
\hline Unauthorized penalty in $1:$ & $\frac{\partial A}{\partial \lambda_{i l 1}}$ & Negative \\
\hline Average skill in h: & $\frac{\partial A}{\partial \bar{x}_{h}}$ & Positive \\
\hline Average skill in 1 : & $\frac{\partial A}{\partial \bar{x}_{l}}$ & Negative \\
\hline Own skill: & $\frac{\partial A}{\partial x_{i l}}$ & Same sign as $-\left(b_{h}-b_{l}\right)$ \\
\hline Return to $\mathrm{HC}$ in $\mathrm{h}:$ & $\frac{\partial A}{\partial b_{h}}$ & Same sign as $-\left(x_{i 1}-\bar{x}_{h}\right)$ \\
\hline Return to $\mathrm{HC}$ in $\mathrm{l}:$ & $\frac{\partial A}{\partial b_{l}}$ & Same sign as $\left(x_{i 1}-\bar{x}_{l}\right)$ \\
\hline \multicolumn{3}{|c|}{ Probability of upward mobility before legalization (Equation 5) } \\
\hline Change in penalty in $1:$ & $\frac{\partial B}{\partial \Delta l_{l}}$ & Positive \\
\hline Change in penalty in $\mathrm{h}$ : & $\frac{\partial B}{\partial \Delta l_{h}}$ & Negative \\
\hline Human capital acquisition: & $\frac{\partial B}{\partial \Delta x_{i 2}}$ & Same sign as $\left(b_{h}-b_{l}\right)$ \\
\hline \multicolumn{3}{|c|}{ Probability of upward mobility after legalization (Equation 6) } \\
\hline Relative penalties: & $\frac{\partial C}{\partial\left(\lambda_{i h 2}-\lambda_{i l 2}\right)}$ & Positive \\
\hline Human capital acquisition: & $\frac{\partial C}{\partial \Delta x_{i 3}}$ & Same sign as $\left(b_{h}-b_{l}\right)$ \\
\hline
\end{tabular}

unauthorized. We assume $F_{I}>0, F_{A}>0$ and $F_{D}>0$. Thus, $Y_{i j t}$ represents expected unauthorized earnings in occupation $j$ in period $t$.

Let us consider two occupations, one $(l)$ which is lower down in the occupational rankings and one $(h)$ which is higher up in the rankings, i.e., $R_{l}<R_{h}$. Suppose that immediately after migrating to the United States, unauthorized workers choose the lower ranked occupation. A necessary - though not sufficient - condition for choosing $l$ over $h$ is that:

$$
b_{l}\left(x_{i l}-\bar{x}_{l}\right)-b_{h}\left(x_{i l}-\bar{x}_{h}\right)+\left(\lambda_{i h 1}-\lambda_{i l 1}\right)>0 .
$$

Selected comparative static results are presented in Table 1 in order to assess the effect of labor market conditions on the likelihood that an unauthorized worker is initially employed in the lower ranked occupation $(l)$. Not surprisingly, these results indicate that there is a negative relationship between the probability of being employed in an occupation and the size of the penalty for being unauthorized. Larger penalties in occupation $h$ increase and larger penalties in $l$ reduce the probability that an unauthorized worker chooses the lower ranked occupation after migration. Similarly, while an in- 
crease in the average skill level of other workers in occupation $l, \bar{x}_{l}$, reduces the probability of unauthorized workers beginning their employment there, increases in the average skill level of workers in the highly ranked occupation, $\bar{x}_{h}$ increase that probability. An increase in a worker's own skill level, $x_{i 1}$, increases the likelihood of employment in the lower ranked occupation whenever the return to human capital is higher in occupation $l$ than in occupation $h$, i.e. whenever $b_{l}-b_{h}>0$. Finally, the probability of a worker being employed in occupation $l$ is increased whenever a worker's human capital level exceeds the average human capital level of other workers employed in that occupation.

Upward occupational mobility - assimilation - occurs when workers who initially choose occupation $l$ immediately after migration to the United States find that over time the earnings in occupation $h$ are higher. This implies that the growth over time in the earnings in occupation $h$ exceeds the earnings growth in occupation $l$ and that the additional earnings growth in $h$ overcomes the first period gap in relative earnings. This is given by,

$$
\Delta Y_{i h}-\Delta Y_{i l}>c
$$

where $\Delta Y_{i h}=Y_{i h 2}-Y_{i h 1}, \Delta Y_{i l}=Y_{i l 2}-Y_{i l 1}$, and $c=Y_{i l 1}-Y_{i h 1}>0$. Alternatively, the above can be written as

$$
\left(b_{h}-b_{l}\right) \Delta x_{i 2}-\left(\Delta \lambda_{h 2}-\Delta \lambda_{l 2}\right)>c
$$

with $\Delta x_{i 2}=\left(x_{i 2}-x_{i 1}\right), \Delta \lambda_{h 2}=\lambda_{i h 2}-\lambda_{i h 1}$, and $\Delta \lambda_{l 2}=\lambda_{i l 2}-\lambda_{i l 1}$.

The effects of selected labor market conditions on the likelihood that an unauthorized worker assimilates prior to amnesty are also given in Table 1. Unauthorized workers can experience pre-legalization upward occupational mobility without investing in human capital. In particular, increases in the penalty for being unauthorized in the lower ranked occupation $l$ promote mobility to occupation $h$, as do decreases in the unauthorized penalty in occupation $h$. These changes in the penalties for being unauthorized are likely to occur because the migrant has acquired occupation-specific information, because the probability of being apprehended has changed (perhaps due to the redirection of INS enforcement efforts), or because the direct wage penalty has changed. Finally, upward occupational mobility can also occur with human capital acquisition if the return to human capital is higher in occupation $h$ than in occupation $l$.

Workers are most likely to choose the lower ranked occupation, $l$, immediately after migration if they have low levels of human capital and occupation $l$ is described by low returns to human capital, low average occupationspecific human capital, and a smaller unauthorized penalty relative to $h$. Upward mobility is most likely to occur when migrants acquire additional human capital which is valued more highly in the higher-ranked occupation or when the change in unauthorized penalties turns to favor the higher-ranked occupation.

We can also predict the impact of amnesty on the occupational assimilation of newly-legalized workers. IRCA's amnesty provision eliminated (for these specific workers) the earnings penalty associated with being unauthorized so that in period $3 \lambda_{i l 3}=\lambda_{i h 3}=0$. From equation (5) it is clear that those workers who remained in the lower ranked occupation prior to legal- 
ization will switch to occupation $h$ after legalization when the following holds:

$$
\left(b_{h}-b_{l}\right) \Delta x_{i 3}+\left(\lambda_{i h 2}-\lambda_{i l 2}\right)>d,
$$

where $\Delta x_{i 3}=\left(x_{i 3}-x_{i 2}\right)$ and $d=Y_{i l 2}-Y_{i h 2}>0$.

Upward occupational mobility can still occur without additional human capital investment if the higher ranked occupation is associated with a higher penalty for being unauthorized. Legalization, then, tends to promote mobility into occupations in which the unauthorized penalty in previous periods was relatively large.

\section{Occupational concentration and mobility of newly-legalized workers}

In this section, we provide a brief description of the occupational concentration and mobility of newly-legalized workers, using information from both of the Legalized Population Surveys (LPS1 and LPS2). In LPS1, respondents were interviewed about their labor market experiences before migration, immediately after migrating as unauthorized workers, and at the time their amnesty application was filed (either in 1987 or 1988). Just over 6000 respondents were in the original sample. In 1992, individuals were reinterviewed about their labor market experiences in 1992 and about other features of their lives. Budget cutbacks and sample attrition resulted in the LPS2 second wave having just over 4000 respondents. ${ }^{8}$ From the LPS data we selected Mexican men who first migrated to the United States between 1968 and 1982.

The occupational distributions of the Mexican men in our sample are presented in Table 2. The first column shows the ten most important (in terms of representation) three-digit occupations held immediately after these men first migrated to the United States. The second and third columns show the same information for the job held at the time the legalization application was filed and at the time of the last interview, respectively. In an effort to evaluate the extent to which workers move out of traditional occupations over time, the bottom of Table 2 documents, for each time period, the percentage of the sample employed in one of the ten traditional occupations (those that were most prevalent immediately after migration) and the percentage in the ten most prevalent occupations in each current time period.

As expected, there is a great deal of occupational concentration for these unauthorized men. Their work lives vividly exemplify activities at the margins of the U.S. labor force. Fully two-thirds of the men in the sample found employment in one of the ten most prevalent occupations immediately after migration to the United States. These jobs offer no surprises. They have long been known to be traditional migrant occupations. For many $(17.3 \%)$, farm work was their first source of employment. This is understandable, given the history of Mexican migration to the United States, and given that more than a third of these men (35.6\%) report having held jobs as farm workers in Mexico immediately before migration. Food counter occupations and groundskeeping were also important sources of employment for men immediately after migration. ${ }^{9}$

These occupations seem to be merely waystations, however, with many men leaving them even before legalization. More than $72 \%$ of the men changed occupation in the interval between their first U.S. job (1968-1982) 
Table 2. Occupational concentration at three points in time for Mexican men

\begin{tabular}{llll}
\hline & $\begin{array}{l}\text { First job in US } \\
(1968-1982)\end{array}$ & $\begin{array}{l}\text { Application job } \\
(1987-1988)\end{array}$ & $\begin{array}{l}\text { Last Job in } \\
\text { US (1992) }\end{array}$ \\
\hline Farm workers & 17.3 & 5.3 & 2.7 \\
Food counter occupations & 15.2 & 6.8 & 3.7 \\
Groundskeepers/Gardeners & 9.3 & 5.9 & 4.2 \\
Janitors/Cleaners & 4.3 & 4.2 & 5.1 \\
Compact. Machine Operators & 3.6 & 4.9 & 6.3 \\
Construction laborers & 3.4 & 2.8 & 4.4 \\
Laborers (except construction) & 3.3 & & 6.7 \\
Cooks (except short order) & 3.0 & 2.5 & 2.6 \\
Twisting machine operators & 2.8 & 2.2 & 2.9 \\
Supervisors handlers, NEC. & 2.5 & 2.8 & 2.9 \\
Assemblers & & 2.2 & 2.7 \\
Auto body repairers & & & 2.7 \\
Sales (Other) & & & 1.7 \\
Brickmasons/Stonemasons & & 1429 & 947 \\
Farmers & 1511 & 44.1 & 37.4 \\
Truck drivers (Light) & 64.5 & & 40.9 \\
N & & 45.1 & \\
\% in traditional (First period) & & & \\
$\quad$ top 10 & 64.5 & & \\
\hline
\end{tabular}

and their job at the time of amnesty application (1987 or 1988). At legalization, only $5.3 \%$ of the sample was working as farm workers. Similarly, the percentage of the sample working in a food counter or groundskeeping occupation fell to $6.8 \%$ and $5.9 \%$, respectively. In spite of the high rate of occupational mobility, however, fully $44 \%$ were employed in one of the ten traditional migrant occupations at the time of legalization.

More than $70 \%$ of men also experienced mobility over the postlegalization period. In 1992, only $2.7 \%$ of the sample was employed as farm workers. At the same time, it is obvious that this mobility represents, at least partly, a churning through these traditional occupations rather than a clear movement away from their unauthorized past. Over $37 \%$ of the men are working in one of the ten traditional occupations, but the emphasis has shifted toward machine operators, cooks, and janitors. Unauthorized workers are likely to represent long-term competition for the native born workers employed in these occupations.

\section{The pre and post legalization mobility of Mexican men}

Occupational mobility is an important feature of the U.S. labor market and millions of U.S. workers each year are employed in different occupations than the year before (Markey and Parks 1989). Only part of this mobility is "upward" mobility. How one interprets relative economic standing depends in part on an understanding of the determinants of occupational mobility. Hall and Kasten (1976), for example, note that if upward occupational mobility is essentially random and all workers have an equal chance of holding a better 
job next year then we need not be overly concerned about individuals at the bottom of the distribution. Alternatively, certain workers may be constrained always to work in the worst jobs. Proponents of the dual labor market hypothesis argue that the potential for advancement is one of the important factors which separates jobs in the primary labor market from jobs in the secondary labor market. Upward mobility is not random, but is related to a worker's characteristics and labor market position. In this section we consider the factors related to mobility for unauthorized workers.

In order to study mobility, we selected Mexican men who were interviewed in both LPS1 and LPS2, who migrated to the United States between 1968 and 1982, and who were less than 64 years old at the last interview data in 1992. These selection criteria resulted in a sample of 849 men. Total upward mobility (using our occupational ranking) in the pre-legalization period was $50.5 \%$ and downward mobility was $20.3 \%$. The low downward mobility partially reflects the fact that it is difficult to be downwardly mobile from the bottom. In the post-legalization period, upward mobility was $38.8 \%$ and downward mobility was $28.8 \%$.

The definitions of the variables and their mean values are presented in Table $3 .{ }^{10}$ The human capital variables include education, whether any education or training had been obtained in the United States, and the degree to which the worker speaks English. Individuals were coded as speaking English well, OK, a little, or not at all (the omitted category). To consider the effects of disrupted labor market experience, we incorporate a measure of whether the worker had made multiple trips across the border because of apprehension or for other reasons. We also include two demographic variables - age and marital status.

In addition to human capital and demographic characteristics, the working conditions of the initial job are assumed to be associated with subsequent mobility. In characterizing working conditions we first consider the effects of the degree of concentration of unauthorized workers in each occupation. This variable acts as a proxy for information flows among unauthorized workers and social networks. We also include the worker's wage in the job at the start of the period to control for the income incentive to change jobs. Additionally, we consider the effects of moving down in the occupational ranking between the last job held in Mexico and the first job in the United States and we include a proxy of the risk of apprehension by INS to see if workers have a higher mobility rate out of occupations where INS enforcement activity is high. ${ }^{11}$ Finally, we include the rank of the initial occupation (the larger the rank number, the lower the occupation is rated) to prevent falsely presenting random mobility as the product of assimilation.

We estimated occupational mobility equations for Mexican men using a multinomial logit specification. This framework allows us to assess the determinants of upward, downward and no occupational mobility between initial U.S. labor market entry and the time of amnesty application (1987 or 1988) and for the direction of occupational mobility between amnesty and $1992 .{ }^{12}$ Specifically,

$$
\operatorname{Pr} o b(Y=j)=\frac{e^{\beta_{j}^{\prime} x_{t}}}{\sum_{j} e^{\beta_{j}^{\prime} x_{t}}}, \quad j=0,1, \ldots J .
$$


Table 3. Aspects of occupational mobility

\begin{tabular}{|c|c|c|c|c|}
\hline & $\begin{array}{l}\text { Entry } \\
(1968-1982)\end{array}$ & $\begin{array}{l}\text { Amnesty app } \\
(1987-1988)\end{array}$ & $\begin{array}{l}\text { Legalized } \\
(1992)\end{array}$ & Definitions \\
\hline \multicolumn{5}{|l|}{ Worker characteristics } \\
\hline Married & 43.3 & 67.1 & 78.8 & Married during time period \\
\hline Age & 21.1 & 30.2 & 34.1 & Age at beginning of time period \\
\hline $0-5$ years education & 30.6 & 30.2 & 29.8 & \multirow{4}{*}{$\begin{array}{l}\text { Number of years of schooling } \\
\text { at beginning of time period }\end{array}$} \\
\hline $6-11$ years education & 52.6 & 52.5 & 53.2 & \\
\hline 12 years education & 12.7 & 13.3 & 10.8 & \\
\hline $12+$ years education & 4.1 & 4.1 & 6.2 & \\
\hline US Experience & 0 & 9.2 & 13.7 & $\begin{array}{l}\text { Potential years in US labor mar- } \\
\text { ket at end of time period }\end{array}$ \\
\hline Any US education & 8.6 & 10.3 & 16.4 & Received some education in US \\
\hline Any US training & - & 6.9 & 17.5 & $\begin{array}{l}\text { Received vocational training in } \\
\text { US }\end{array}$ \\
\hline English well $^{\mathrm{a}}$ & 15.5 & 44.1 & 47.8 & $\begin{array}{l}\text { English best language (EBL) or } \\
\text { can do } 6 \text { tasks }\end{array}$ \\
\hline English $\mathrm{OK}^{\mathrm{a}}$ & 33.4 & 12.9 & 14.5 & Not EBL, can do 45 tasks \\
\hline English little $^{\mathrm{a}}$ & 13.7 & 15.2 & 16.2 & Not EBL, can do 2-3 tasks \\
\hline English none $^{\mathrm{a}}$ & 37.4 & 27.8 & 21.5 & $\begin{array}{l}\text { Not EBL, can do } 1 \text { or no tasks, } \\
\text { omitted category }\end{array}$ \\
\hline \multicolumn{5}{|l|}{ Job conditions } \\
\hline $\begin{array}{l}\text { Undocumented } \\
\text { Concentration }\end{array}$ & 6.3 & 3.6 & 2.8 & $\begin{array}{l}\text { Weighted percent of LPS re- } \\
\text { spondents in same occupation }\end{array}$ \\
\hline Real wage & $\$ 4.95$ & $\$ 5.61$ & $\$ 6.13$ & $\begin{array}{l}\text { Hourly wage in first job of the } \\
\text { time period }\end{array}$ \\
\hline Mexico/US & 52.3 & - & - & $\begin{array}{l}\text { First US job was lower in } \\
\text { ranking }\end{array}$ \\
\hline \multicolumn{5}{|l|}{ Downward mobility } \\
\hline INS & 10.5 & - & - & $\begin{array}{l}\text { Intensity of INS apprehensions in } \\
\text { first job of time period }\end{array}$ \\
\hline Multiple trips & - & 40.9 & - & Entered the US more than once \\
\hline Rank & 146.8 & 131.6 & 127.4 & Rank of first occupation \\
\hline Occupational mobility & \multicolumn{2}{|c|}{ Pre legalization } & \multicolumn{2}{|c|}{ Post legalization } \\
\hline Upward & \multicolumn{2}{|c|}{50.6} & \multicolumn{2}{|l|}{39.5} \\
\hline None & \multicolumn{2}{|l|}{27.7} & \multicolumn{2}{|l|}{30.7} \\
\hline Downward & \multicolumn{2}{|l|}{21.7} & \multicolumn{2}{|l|}{29.8} \\
\hline
\end{tabular}

a The six English tasks considered were: reading newspapers, magazines, or instructions, and speaking on the telephone, with a sales clerk, or with a doctor, nurse or teacher.

In our case, there are three possible mobility outcomes $(j)$ : no change, upward, or downward. To identify the model we choose no mobility to be the base case and impose the standard normalization that $\beta_{0}=0 .{ }^{13}$ Multinomial logit coefficients are presented in Table 4.

What separates those who change occupations over the pre-legalization period (1968-1982 - 1987 or 1988) from those who do not? Our analysis suggests that four important factors drive the occupational mobility. First, English language ability promotes occupational change, both upward and downward. Unauthorized workers who speak English well or OK are much more likely to be upwardly mobile than their counterparts who do not speak English at all. At the same time, workers who speak any English at all are also more likely to be downwardly mobile than workers who speak no English. 
Table 4. Determinants of pre and post legalization occupational mobility for Mexican men (Multinomial logit coefficients and standard errors)

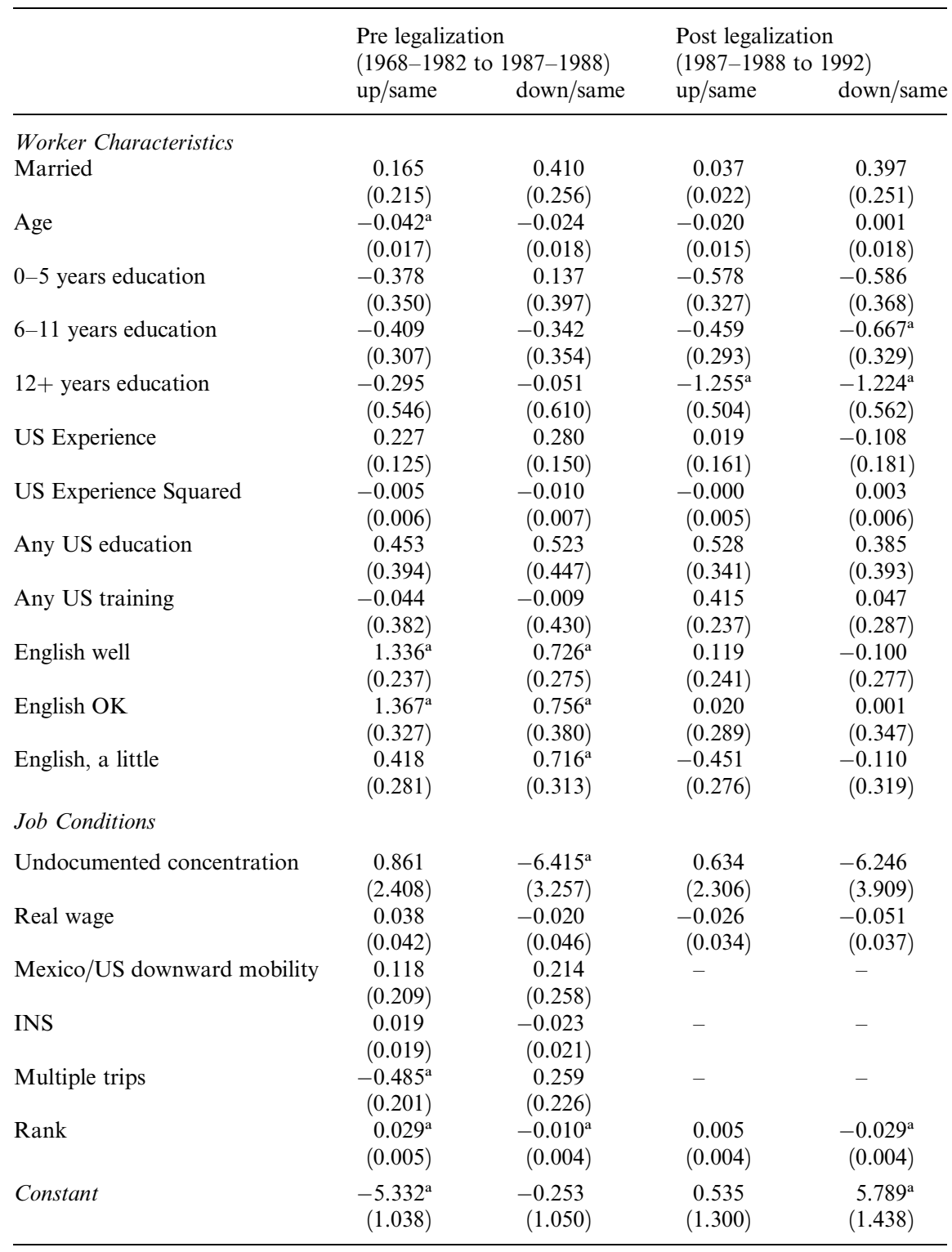

${ }^{\text {a }}$ Indicates significance at the $5 \%$ level

Without further information, we can only speculate about the connections between English language ability and movement in the labor market. There are, however, several possible connections. First, speaking English may lead to promotions (upward mobility) within a single firm or with a single employer. That is, someone who speaks English can move from a job that doesn't require English (like farm worker) to one that does (like supervisor or 
marketer) without ever changing employers. This may represent an important source of mobility for unauthorized workers who wish to stay with a "safe" employer while moving up the firm's hierarchy. Second, speaking English well can be a signal to employers about a person's motivation and ability especially when formal credentials, like high school diplomas, are missing or are irrelevant.

Although the relationship between English language skills and upward occupational mobility is intuitive, it is more difficult to explain why better English language skills also result in downward mobility relative to remaining in the same occupation. Speaking English appears to enable unauthorized workers to expand their job searches. English skills make it easier to communicate with more U.S. employers and to develop more job search strategies, like reading the want ads in U.S. newspapers. Individuals who do not speak English are much more likely to remain in their initial occupations.

Second, relative to remaining in the same occupation over time, unauthorized workers employed in occupations where other unauthorized workers congregate are much less likely to experience a fall in their occupational ranking. Thus, a social network of other unauthorized workers appears to provide an important safety net for workers by reducing the chances of downward mobility.

Third, those who have made multiple trips across the border, perhaps because of apprehensions, are much less likely to experience upward mobility than those whose experience in the United States has been continuous. Workers who are apprehended may have to "start all over again" when they return to the United States. This interruption to U.S. experience is costly in terms of upward mobility.

The companion to multiple trips across the border is the risk of apprehension. We document this risk by an index that relates the relative intensity of apprehensions on the job by the INS. Surprisingly, this variable is not at all associated with the probability of upward mobility, nor is it associated with downward mobility. Overall, this suggests that employment in a high-risk job is associated with occupational stability. This finding may occur because our measure is rough and may be correlated with unmeasured characteristics of the workers who tend to start out in those high-risk jobs.

Finally, where an individual starts in the occupational hierarchy has a bearing on their chances of subsequent mobility. Unauthorized workers who begin their U.S. careers lower in the occupational rankings have a higher probability of upward and a lower probability of downward mobility. ${ }^{14}$ This may suggest that occupational mobility is at least in part random. To see this, suppose that changes in occupations were completely random in the sense that in each period workers drew randomly from the occupational distribution, then the probability of experiencing upward occupational mobility would be greater for those at the bottom of the occupational hierarchy. Any occupational change for individuals in the lowest ranked occupation would be measured as upward mobility. Similarly, individuals in the highest ranked occupation could experience only downward mobility. The upward occupational mobility of immigrants documented by others may be the result of assimilation and the accumulation of U.S.-specific human capital, or it may result from starting lower than natives in the occupational hierarchy and then experiencing random occupational changes.

Interestingly, but not unexpected in light of previous studies, is the fact 
that formal credentials do not make a difference in the probability of mobility in the unauthorized period. Total schooling, schooling in the United States, U.S. experience and U.S. training all fail to promote mobility. Once again, without more information we can only speculate why this is so. It is important to remember, however, that the average number of years of formal schooling is about eight - not even a year spent in high school. This schooling also took place in Mexico, not in the United States. Another year of schooling, say comparing eight years with nine years, simply isn't important enough for U.S. employers to use as a basis for hiring, firing or differentiating unauthorized Mexican employees. Employers are much more likely to use easily observable characteristics, like strength, motivation, or English ability to make their employment decisions.

More interesting is the apparent lack of an effect of the first job's wage. This may suggest that unauthorized workers do not respond to the economic incentives and conditions of the job. On the other hand, for many of these workers, U.S. wages are extremely high relative to Mexican wages. If the job is relatively safe from INS and provides a steady income it may make sense for the worker to remain in that job than to marginally improve hourly wages at the risk of moving to a job where the likelihood of apprehension might be higher.

For Mexican men, all of the empirical work leads to a simple conclusion: English language ability and job characteristics are strongly correlated with occupational mobility in the unauthorized U.S. labor market. Those workers who can communicate in English, who began lower in the occupational ranking, and who have remained in the United States continuously all experience higher probabilities of upward occupational mobility than otherwise similar workers.

These men experience a high rate of occupational mobility after legalization. In just over 4 years, more than $70 \%$ of them report changing occupations. Still, few of the individual or job characteristics that were considered seem to be important in predicting the direction of that occupational change (see Table 4). Only one of the characteristics - initial employment towards the bottom of the occupational rankings - identified as important for prelegalization mobility is significantly related to mobility patterns after these workers have amnesty under IRCA. Interestingly, the highest measured level of education, having more than a high school degree, is associated with occupational stability while having less than a high school degree is associated with a higher probability of remaining in the same occupation relative to moving downward. Overall, however, relative to pre-legalization mobility, few characteristics surpass in importance the now common experience of having legal papers.

\section{Conclusions}

Understanding occupational concentration and occupational mobility over time is central to understanding the extent to which unauthorized workers compete with specific groups of U.S. workers. We shed light on this issue by studying the occupational concentration and the determinants of occupational mobility of a group of Mexican men who entered the U.S. labor market as unauthorized workers and received amnesty under IRCA. 
Fully two-thirds of the men in our sample began their U.S. work lives in one of ten three digit occupations. These occupations - primarily farm work, groundskeeping, and food counter occupations - exemplify work at the margins of the U.S. labor market. They seem, however, to be merely stepping stones to others; more than $72 \%$ change occupation between labor market entry (1968-1982) and the legalization application (1987 or 1988) and more than $70 \%$ change occupation between the legalization application and 1992.

Several broad patterns stand out from our analysis. Pre-legalization mobility is principally driven by English language ability and job characteristics. These variables tend to explain a propensity toward both upward and downward mobility. It is quite possible that knowing English, or having spent more years in the United States, simply gives an unauthorized worker the ability to move from job to job, possibly maximizing his own opportunities within a limited labor market. ${ }^{15}$ Understanding how English operates to improve opportunities is an important future area for research. Does English language ability improve opportunities because it enables the migrant to do more jobs or does it improve opportunities by broadening the job search horizon? Does English ability simply provide signals about motivation and innate ability to employers who are unable to rely on other known credentials when hiring migrants?

We found that legal occupational mobility has few obvious correlates. We speculate, but cannot ascertain with certainty, that legal status acts like a union card and swamps most other characteristics. In would be interesting to conduct similar mobility studies for other groups of amnesty recipients. Is this only true for Mexican men, or does it hold for the entire legalized population? We must find the answer to these questions in order to assess the success of IRCA in improving work opportunities.

Finally, we also observe a relationship between working in occupations where other unauthorized workers are concentrated and occupational mobility. For unauthorized workers, the social relations of employment may enhance their lives and provide a more amenable atmosphere to continued employment when they face the constant threat of apprehension. Our own findings for these Mexican men are inconclusive but deserve further investigation. Further research may illuminate the working lives of both unauthorized and legalized workers. It would be interesting to explore the apparent lack of relationship between wages and job mobility of any kind. A detailed study of the wage-mobility relationship could explain why this absence exists. It is quite possible that these workers do not change jobs in response to low wages, but that when they do change jobs they do so in order to earn higher wages.

Interestingly, there is also only a weak relationship between investment in additional human capital in the United States (like more schooling, job training or labor market experience) and occupational mobility. Traditional studies of assimilation would lead us to believe that these investments are the vehicles of mobility in the United States, yet they do not appear to promote mobility for newly-legalized workers. At the same time, we do find that where one begins in the occupational ranking has important implications for subsequent mobility. This along with the weakness of individual characteristics in explaining occupational mobility suggest that mobility may, to some extent, be random. 
We conclude that IRCA did indeed change mobility patterns for the legalized population. Legal status, itself, creates a whole new set of opportunities and, on average, these workers are employed in occupations that are higher up the occupational ladder (see Table 3). We do not yet understand the exact mechanisms that operationalize those opportunities. Undoubtedly, some changes occur in the workers' behavior and some in employers' attitudes toward them. With our micro data set that only contains information on the workers, themselves, it is impossible to sort these separate changes.

\section{Appendix \\ Occupational rankings}

Occupations, by their very nature, are complex entities with many facets. There are both pecuniary and non-pecuniary reasons for choosing or being chosen to work in an occupation. It is difficult to use a single index to determine which occupations are better and which are worse. Yet we all have perceptions about "good" and "bad" occupations. A doctor is a "good" occupation while a sweatshop sewing machine operator is a "bad" occupation. Our analysis rests on the assumption that it is desirable and possible to numerically rank occupations based on pecuniary returns. Ranking allows us the freedom to talk about all occupations rather than a few occupation groups.

Our ranking of occupations is based on occupation-specific wage distributions. The data are from the one in one thousand 1980 U.S. census sample which, because of its large sample size, allows us to rank occupations based on their three digit occupational classifications. The initial rankings were based on over 115,000 working men. Some three digit classifications were bundled together because some occupations have very few people in them even in U.S. census samples (like funeral directors and auctioneers) and because some three digit occupations represent tasks that are effectively indistinguishable (like order clerks and billing clerks). Altogether, 180 separate occupations were ranked.

Although we have used several methods of ranking, for this paper we use what we call the "lower bound" rankings. We estimated (three-digit) occupation specific hourly wage regressions and found the occupation's value, $R_{j}$, by subtracting the standard deviation of the expected wage $\left(\hat{\sigma}_{\bar{w}_{j}}^{2}\right)$ from the expected wage $\left(\bar{w}_{j}\right)$ in the occupation. The expected, rather than the actual, standard deviation was used to mitigate the effects of unobservable characteristics that drive occupational wages at the top and bottom of the wage distribution. Then the values were placed in rank order, with the largest value assigned Rank $=1$ and the smallest value assigned Rank $=180$. Specifically,

$$
\begin{aligned}
& w_{i j}=\sum_{k} \beta_{j k} X_{i j k}+\varepsilon_{i j} \\
& \bar{w}_{j}=\hat{\beta}_{j k} \bar{X}_{j k}
\end{aligned}
$$




$$
\begin{aligned}
\hat{\sigma}_{\bar{w}_{j}}^{2}= & \sum_{k}\left(X_{i j k}-\bar{X}_{j k}\right)^{2} \operatorname{var}\left(\hat{\beta}_{j k}\right) \\
& +2 \sum_{a<k}\left(x_{i j a}-\bar{X}_{j a}\right)\left(x_{i j k}-\bar{X}_{j k}\right) \operatorname{cov}\left(\hat{\beta}_{j a}, \hat{\beta}_{j k}\right)+\frac{\sigma_{w_{j}}^{2}}{n} \\
R_{j}= & \bar{w}_{j}-\hat{\sigma}_{\bar{w}_{j}}
\end{aligned}
$$

let $l_{j}=1$ if $R_{l}>R_{j}$ else $l_{j}=0$

$$
\operatorname{Rank}_{j}=\sum_{\substack{l=1 \\ l \neq j}}^{J} l_{j}+1,
$$

where $i$ indexes individuals, $j$ indexes occupations, and $k$ indexes independent variables used in the equation. A unique ranking is assigned to every occupation as long as the strict inequality holds. ${ }^{16}$

The ranking has several attractive features. All else equal, occupations with high expected wages are ranked higher than occupations with low expected wages. If two occupations have the same expected wage, the riskier occupation (in terms of the wage distribution) will be ranked lower. Occupations that have looser entry requirements (empirically measured by the mean square deviation of human capital characteristics) are ranked lower than those with tighter entry requirements.

\section{Endnotes}

1 IRCA provided for two legalization programs: the "General" legalization program and a Special Agricultural Workers (SAW) program. The SAW population was not interviewed and it is outside the purview of this paper.

2 IRCA in this sense provides a "natural experiment" for studying the effects of legal status. We do not have access to a control group. There is no corresponding longitudinal information about a group of unauthorized workers who were randomly denied amnesty.

3 Topel and Ward (1992:460) argue that for natives "about one third of total earnings growth during the first ten years of labor market experience is attributable to job changing activity." Chiswick (1978b) points to the importance of occupational mobility for the assimilation of immigrants.

4 The results of this early research on assimilation have been challenged on several grounds. First, this pattern of assimilation does not appear to hold across the board with the return to U.S. labor market experience varying significantly across different immigrant groups (Long 1980; DeFreitas 1981; Borjas 1982; Tienda 1983; Kossoudji 1989). Second, most research on the assimilation of immigrants has used cross-sectional data and conclusions about the progress of immigrants over time have been reached by comparing different cohorts of immigrants entering the United States at various points in time (see Borjas 1985). Third, the data often combine groups of immigrants who might be quite different (see Kossoudji 1989).

5 This result, however, is based on a sample of workers which includes legal "non-immigrants", i.e., persons holding a temporary visa (such as foreign worker, tourist, or student visa) as well as unauthorized workers.

6 See Duleep and Regets (1997) for a model of immigrant investment in human capital.

$7 R_{j}$ translates to the rank of the occupation. After experimentation in earlier work (Cobb-Clark and Kossoudji 1994) we operationalize $R_{j}$ by considering both the expected wage and the standard deviation of the expected wage. Occupations with high variances are ranked lower 
than similar low variance occupations. Professional athletes, for example, which is ranked $103^{\text {rd }}$ under the mean wage falls to $172^{\text {nd }}$ under this ranking. See the Appendix.

8 For more information about this sample attrition see Singer 1994.

9 Unauthorized women exhibit even more occupational concentration than unauthorized men and over time their occupational mobility rates are lower (Cobb-Clark and Kossoudji 1998). Data for authorized workers from the National Longitudinal Survey of Youth suggest that natives are much less concentrated in traditional migrant industries and occupations (Kossoudji and Cobb-Clark 1998).

10 Because we are interested in mobility equations, we have tried, where possible to define all variables from the beginning of the period over which the mobility is measured. Sometimes this is not possible or desirable. The English language and U.S. experience variables, for example refer to the end of the period.

11 This variable was calculated using INS workplace apprehension figures by industry. It ranges from a low of zero to a high of sixteen.

12 The occupational rankings, which are used to determine the direction of mobility, are based on the average and standard deviation of wages for all U.S. men working in an occupation. Technical details are discussed in the appendix.

13 Within the multinomial logit models, the log odds of being in any category are compared with a base category. In these models, the coefficient of the base category (in this case, remaining in the same occupation) are normalized to zero and the reported coefficients are relative to those in the base category.

14 Recall that a higher value for the rank variable indicates that an occupation that is lower in the occupational rankings.

15 Acquiring English language ability may be correlated with the intention to remain in the United States (see Duleep and Regets 1997).

16 We also created a ranking which allowed occupations with exceptionally close values of $P_{j}$ (within one percent) to be assigned the same rank. The results using this ranking which allowed for ties between close occupations were substantially the same.

\section{References}

Altonji JG, Card D (1991) The Effects of Immigration on the Labor Market Outcomes of Lessskilled Natives. In: Abowd JM, Freeman RB (eds) Immigration, Trade, and the Labor Market. The University of Chicago Press, Chicago, 201-234

Bean FD, Telles E, Lowell BL (1987) Undocumented Migration to the United States: Perceptions and Evidence. Population and Development Review 13(4):671-690

Bean FD, Lowell BL, Taylor LJ (1988) Undocumented Mexican Immigrants and the Earnings of Other Workers in the United States. Demography 25(1):35-49

Borjas GJ (1985) Assimilation, Changes in Cohort Quality, and the Earnings of Immigrants. Journal of Labor Economics 3(4):463-489

Borjas GJ (1982) The Earnings of Male Hispanic Immigrants in the United States. Industrial and Labor Relations Review 35(3):343-353

Borjas GJ (1987) Immigrants, Minorities, and Labor Market Competition. Industrial and Labor Relations Review 40(3):382-392

Chiswick BR (1978a) The Effect of Americanization on the Earnings of Foreign-born Men. Journal of Political Economy 86(5):897-921

Chiswick BR (1978b) A Longitudinal Analysis of the Occupational Mobility of Immigrants. In: Madison D (ed) Proceedings of the 30th Annual Winter Meetings of the Industrial Relations Research Association. University of Wisconsin Press, Madison, 20-27

Chiswick BR (1988) Illegal Aliens: Their Employment and Employers. W.E. Upjohn Institute for Employment Research, Kalamazoo, MI

Cobb-Clark D, Kossoudji SA (1994) IRCA Legalization and the Occupational Concentration and Mobility of Amnestied Immigrants. Report to the U.S. Department of Labor

Cobb-Clark D, Kossoudji SA (1998) Mobility in El Norte: Employment and Occupational Changes for Undocumented Latina Women. Social Science Quarterly (forthcoming)

DeFreitas GE (1981) What is the Occupational Mobility of Black Immigrants. Monthly Labor Review April: 44-45 
Duleep HO, Regets MC (1997) Measuring Immigrant Wage Growth Using Matched CPS Files. Demography 34(2):239-250

Espenshade T (1992) Immigrants, Puerto Ricans, and the Earnings of Native Black Males. In: Jaynes G (ed) Blacks, Immigration, and Race Relations.

Grossman JB (1982) The Substitutability of Natives and Immigrants in Production. Industrial and Labor Relations Review 37:240-251

Hall RE, Kasten RA (1976) Occupational Mobility and the Distribution of Occupational Success Among Young Men. Proceedings and Papers of the American Economic Association 66(2):309-315

Jasso G, Rosenzweig M (1985) Estimating the Effects of Experience in the United States on the Occupational Mobility of Immigrants. Mimeo, University of Minnesota

Jasso G, Rosenzweig M (1990) The New Chosen Peoples: Immigrants in the United States. Russel Sage Foundation Press, New York

Jones RC, Murray WB (1986) Occupational and Spatial Mobility of Temporary Mexican Migrants to the U.S.: A Comparison Analysis. International Migration Review 20:973-985

Kossoudji SA (1989) Immigrant Worker Assimilation: Is It a Labor Market Phenomenon? The Journal of Human Resources 24(3):494-527

Kossoudji SA, Cobb-Clark DA (1996) Finding Good Opportunities within Undocumented Markets: U.S. Occupational Mobility for Latino Workers. International Migration Review 30(4):901-924

Kossoudji SA, Cobb-Clark DA (1998) Coming Out of the Shadows: Learning about Legal Status and Wages from the Legalized Population. Mimeo

LaLonde RJ, Topel RH (1991) Labor Market Adjustments to Increased Immigration. In: Abowd JM, Freeman RB (eds) Immigration, Trade, and the Labor Market. The University of Chicago Press, Chicago, 167-199

Long JE (1980) The Effect of Americanization on Earnings: Some Evidence for Women. Journal of Political Economy 88(3):620-629

Markey JP, Parks W (1989) Occupational Change: Pursuing a Different Kind of Work. Monthly Labor Review September: 3-12

Miller PW (1987) Aspects of Occupational Mobility and Attainment Among Immigrants in Australia. International Migration Review 21:96-113

Singer A (1994) Changes in the Employment and Earnings of the Legalized Population. Final Report to the Department of Labor. Mimeo

Tienda M (1983) Nationality and Income Attainment Among Native and Immigrant Hispanic Men in the United States. The Sociology Quarterly 24:253-272

Topel R, Ward M (1992) Job Mobility and the Careers of Young Men. Quarterly Journal of Economics 107:439-479

U.S. General Accounting Office (1988) Illegal Aliens: Influence of Illegal Workers on Wages and Working Conditions of Legal Workers (GAO/PEMD-88-13BR) 